\title{
A!
}

This is an electronic reprint of the original article.

This reprint may differ from the original in pagination and typographic detail.

Chun, Namkyu; Gurova, Olga

Place-Making the Local to Reach the Global

Published in:

Fashion Practice

DOI:

$10.1080 / 17569370.2018 .1507168$

Published: 08/12/2018

Document Version

Peer reviewed version

Please cite the original version:

Chun, N., \& Gurova, O. (2018). Place-Making the Local to Reach the Global: A Case Study of Pre-Helsinki.

Fashion Practice, 11(1). https://doi.org/10.1080/17569370.2018.1507168

This material is protected by copyright and other intellectual property rights, and duplication or sale of all or part of any of the repository collections is not permitted, except that material may be duplicated by you for your research use or educational purposes in electronic or print form. You must obtain permission for any other use. Electronic or print copies may not be offered, whether for sale or otherwise to anyone who is not an authorised user. 


\section{Place-making the local to reach the global: a case study of Pre Helsinki}

\section{Namkyu Chun}

Department of Design, Aalto University School of Arts, Design and Architecture, Helsinki, Finland

\section{Olga Gurova}

Department of Culture and Global Studies, Aalborg University, Aalborg, Denmark

Corresponding author: Namkyu Chun (e-mail: namkyu.chun@aalto.fi)

Namkyu Chun is a doctoral researcher at Aalto University. By investigating the notion of fashion thinking, his research aims at establishing a dialogue between fashion and design research in order to introduce expanded roles of fashion designers beyond dressing the public.

Olga Gurova ( $\mathrm{PhD}$, Cultural Studies) is an assistant professor in consumption studies at Aalborg University, Denmark. Her research interests include consumption studies, fashion studies and qualitative methods of social research. 


\section{Place-making the local to reach the global: a case study of Pre Helsinki}

This article analyzes the case of Pre Helsinki, a designers-driven platform aiming at internationalizing Finnish fashion talents. This case illustrates how fashion designers through this platform mobilize local actors to reshape Finnish fashion further to increase its visibility at the international level. For this inquiry, the article develops the concept of place-making, which summarizes the collective efforts of fashion designers and other local actors in the internationalization of Finnish fashion. Place-making comprises three themes. First, it implies the dynamic and consolidated interplay among the local actors. Second, it is characterized with economic and symbolic contributions of the actors to the local development. Third, place-making is implemented at multiple scales, from neighborhood to city and nation. The data for analysis are retrieved from semistructured interviews with fashion designers and local actors of Finnish fashion industry and from ethnographic observation. The research shows how Pre Helsinki was appeared as a reaction to two main disconnections in the Finnish fashion, namely, a disconnection between the design and business sides in the local fashion scene and a disconnection between the local and international fashion scenes. The research illustrates how and to what extent these disconnections were addressed in the activities of Pre Helsinki. The background, origin of the platform, its activities and main actors are discussed in the context of how the platform implements place-making and contributes to building a meaning of Helsinki and Finland as places of fashion. The external and internal tensions and the future prospects of the platform are also discussed. In conclusion, the emergence of Pre Helsinki is scrutinized in the broader context of current development of Finnish fashion ecosystem and its stage.

Keywords: place-making; fashion design; Finnish fashion; Nordic fashion

\section{Introduction: up-and-coming Finnish fashion}

Despite the fact that globalized fashion industry tends towards extreme centralization with high significant of fashion capitals, it has been shown that the classic centerperiphery model has been replaced by polycentric model of global fashion (Skov 2011). While such cities as Paris, London, Milan and New York hold the name of global 
fashion capitals, emerging cities and countries, for instance, Copenhagen in Denmark and Stockholm in Sweden from the Nordic region, have been more oriented to 'international validation' and seek to be included in 'macro-level transnational dynamics' (Skov 2011: 139). These cities and countries strive to become known as places of fashion, fashion cities and fashion nations in other words.

These attempts of Nordic countries to gain recognition in global fashion have been acknowledged and analyzed in scholarly literature. Studies on Danish fashion, for instance, have introduced how the country developed the local fashion scene while embracing the national identity to communicate it on the global scale (Riegels Melchior 2010, 2011; Riegels Melchior, Skov and Csaba 2011). Meanwhile, several studies on Swedish fashion stressed the notion of place and its relationship with local fashion firms (Hauge, Malmberg and Power 2009; Hauge 2012). These studies explored how 'highcost' countries, such as Sweden, can retain a sizeable presence in global fashion and how localized recourses, including knowledge and networks, make the fashion companies keep their home base in the country (Hauge, Malmberg and Power 2009).

More recently, another Nordic country Finland has been actively involved in the process of establishing itself in the global fashion landscape (Pöppönen 2016). These attempts can be found, for instance, in numerous cases of the international recognition of young Finnish fashion designers who were awarded prizes in prestigious competitions, such as Hyères International Festival of Fashion and Photography ${ }^{i}$ and LVMH prize ${ }^{\text {ii }}$ (Pöppönen 2016; Voight 2016), in growing appraisals of Finnish fashion designers in international media, such as Vogue Italia, and in gradually expanding Finnish brands, such as Samuji and Makia Clothing. However, these attempts show that at the moment this international recognition rather refers to artistic fashion than to commercial brands, which is the case of Denmark and Sweden. Therefore, the recent 
development of Finnish fashion is often compared to the Belgian fashion phenomenon (see Grayson 2013; Moreno 2015; Pechman 2016), which gained the reputation from the 'Antwerp Six' 'iii, an avant-garde group of Belgian designers in the 1980s (GimenoMartinez 2007, 2015; Teunissen 2011).

However, Finland, being a 'second-tier region' in fashion (Skov 2011), has rarely attracted scholarly attention (see, however, Gurova and Morozova 2016; Chun, Gurova and Niinimäki 2017, McNeil 2017). ${ }^{\text {iv }}$ This attention is needed not only because it can shed light on yet another Nordic case, but also because it can exemplify how fashion designers have been able to mobilize local actors through a designers-driven platform that they created to increase the international recognition of Finnish fashion and to push the whole ecosystem of Finnish fashion forward. To view this development, we employ the concept of place-making, summarizing it as collective efforts of local actors to position an emerging 'fashion nation' (Riegels Melchior 2011) on global fashion stage.

Scholars have agreed that Finland has established its reputation as a 'design nation' (Riegels Melchior 2011; Skov 2011) together with neighboring Nordic countries. From the tradition in applied arts, the country has introduced iconic designs since the golden age of Finnish design in the 1950s and 1960s (Korvenmaa 2010; Hohti 2011). Finland became a meaningful place for design through the continuous recognition at international fairs in Paris, Milan and New York (Davies 2002). Despite not being clearly positioned globally as a fashion nation yet, for many years, Finnish fashion has been described as ‘up-and-coming' (see Szmydke and Folcher 2013; Petersen 2015; Sjöroos 2016). But for how long can this description be applied? Helsinki, the capital of Finland, is still a novel name in fashion compared to other cities in Nordic countries, such as Stockholm in Sweden and Copenhagen in Denmark. 
Particularly from a business perspective, several reports noted how Finnish fashion companies and brands struggle to reach the international markets (Lille 2010; Van Eynde and Wiinamäki 2012). These studies commonly recognized the necessity of remodelling the Finnish fashion ecosystem in order to support striving local fashion business.

To overcome this struggle, the Helsinki fashion scene has presented a joint effort, organizing an initiative that represents a set of activities under the roof a new type of fashion week. In 2012, both fashion designers and business experts from Finland initiated a unique platform known as Pre Helsinki (Chun, Gurova and Niinimäki 2017). This platform differs from other fashion weeks that hold periodic fashion shows of several labels. Instead, it is a designers-centered and designers-driven platform that aims at internationalizing young Finnish fashion talents. As designers have been involved in both the organization of the platform and their promotion through the platform, it is a timely case to demonstrate how this platform contributes to create a meaning of Helsinki and Finland as places for fashion. We argue that this platform exemplifies how Finnish fashion actors have been seeking for a different and unique path with the emphasized role of fashion designers while increasing international visibility of Finnish fashion. Comparing to previously mentioned examples from its neighbors, Sweden and Denmark, where mobilization of the local actors in their attempts to promote and internationalize fashion was facilitated by the Danish Fashion Institute and Swedish Fashion Council, Finland lacks such an organization. To some extent, Finnish Fashion and Textile (Suomen Tekstiili ja Muoti in Finnish) is an organization that promotes Finnish fashion in the country and globally, but it is based on the membership, provides services for its members only. The members are mainly companies rather than start-ups. This organization also focuses primarily on supporting commercial fashion instead of 
artistic fashion. Therefore, Pre Helsinki initially has taken exactly this niche - to promote globally young Finnish fashion designers who both have already gained international recognition; thus are capable of attracting attention of international media and eventually can become a part of international business on fashion.

According to previous works (Rantisi 2011; Skov 2011; McRobbie 2015), placemaking emphasizes dynamic interactions amongst local actors in the process of building a meaning of place, for instance, a city as fashion city and a country as fashion nation. During this process, the central role is played by designers to mobilize the efforts of other local actors, such as policy makers and local businesses. Thus, this study aims at exploring the ways in which Pre Helsinki has implemented place-making. Therefore, our goal in this article is neither to define what Finnish fashion identity is nor to unpack the modern history of Finnish fashion, but rather to utilize Pre Helsinki as a case study to view the progression of Finnish fashion ecology and to trace how it has catalysed the local development to acquire international recognition through consolidated collaborative actions.

For this inquiry, we will introduce previous studies on place-making in the first section and suggest our definition for the concept. Then, we will proceed to the discussion of how place-making is implemented taking a closer look at the case of Pre Helsinki.

\section{Theoretical Foundations: place-making and fashion designers}

The relationship between fashion and a place has been studied through different lenses, such as how fashion education and policy shape the place, what are particular styles linked to certain places, what is the role of production and consumption in the place development (e.g. McRobbie 1998; Skov 2001; Niessen, Leshkowich and Jones 2003; Crewe 2017). Among many other possibilities to connect fashion with the notion of 
place, this paper pays special attention to the idea of making a meaning of place throughout fashion activities.

Place-making, the key concept of this article, has been borrowed from the study of Skov (2011). Expanding from her earlier studies on fashion in East Asian contexts, such as Japan and Hong Kong (Skov 2001, 2003), she examined industrial, cultural and governmental issues in the evolution of local fashion scenes in Europe. She argued that recently global fast fashion companies have taken the role of dressing the nation from fashion designers and questioned: "what do fashion designers produce that is significant for the nation?" $(2011,150)$. To highlight the impact of fashion design in a spatial dimension, she introduced the place-making ability that "fills a cosmopolitan form with local content through displays and events associated with a heightened sense of hereand-now" $(2011,138)$. According to her study, the ability is connected with a particular territory as it helps boost the local culture and economy. In particular, the role of young fashion designers is stressed in the local development due to their active involvement in place-making.

Closely related to this view from Skov (2011), Rantisi (2011) differentiated the place-making ability of fashion design from place-marketing (or place-branding). For the place-making ability, she stressed the importance of dynamic interaction and coordination between actors in the local fashion industry beyond 'localized capabilities', the presence of key local industry activities, such as revisiting traditional technique, production, design, marketing and distribution. By reconnecting these existing capabilities, the place-making ability can channel diverse supports to generate a regional transformation through fashion design. However, according to Rantisi (2011), the place-marketing is mostly conducted through a top-down and hierarchical governmental policy that restricts the bottom-up development of local fashion 
dynamics. This distinction between top-down and bottom-up approaches can be traced from her previous study on Montreal fashion where the interaction between fashion designers and cultural intermediaries, such as showrooms and buyers, was investigated (Rantisi 2010).

In comparison to these studies on place-making, Segre Reinach (2011) paid more attention to international recognition of national identity in fashion. Together with Rantisi's place-marketing ability, the view of Segre Reinach stressed the strong influence of fashion design in the creation of a new regional identity. The "catwalk economy' of fashion allows countries to involve in the exchange of various matters from business to culture through carefully choreographed and refined presentation of novelty (Löfgren and Willim 2005). Thus, she alarmed overlooking the impact of fashion design in building a national identity.

Development trajectories of fashion in Scandinavian countries, including Denmark, Sweden and Norway, was introduced by Riegels Melchior (2011) as additional examples of the government driven branding effort for small nations. By comparing their approaches, she illustrated the ways in which the three countries have transformed their images from design nations to fashion nations. By forming strong partnerships between governments and local fashion actors, these countries have successfully renewed their national identity to be more attractive and forward-looking in order to be accepted in the global dialogue of fashion.

More recently, a study investigating the place-making ability of fashion design focused on a smaller scale of a neighborhood rather than the national level. From a set of studies on urban creative professionals in different contexts, McRobbie (2015) introduced a case of Berlin-based fashion designers as another example of the placemaking ability. She argued that Berlin tends to have less commercial and more artistic 
preferences in terms of fashion. As a reinterpretation of this tendency, several female fashion designers have demonstrated an example of place-making from nonindustrialized firms in a small area of the city. In other words, throughout their independently developed and socially engaging local stores, those designers acted as activists to construct a new movement to support female employment and economic independence in a particular neighborhood in Berlin.

Based on these studies, we introduce place-making as a concept that embraces three themes. The first theme is the involvement of diverse actors in the implementation of place-making, including young designers, local fashion stakeholders as well as governmental organizations. This involvement can include many ways of support, such as finance, media, facility and personal network. The studies of Skov (2011) and McRobbie (2015) highlighted the active role of young fashion designers in placemaking although dynamic interplay of stakeholders in the local fashion scene was also commonly recognized as an essential element. While embracing the interconnectivity of the stakeholder, the supportive role that governmental organizations have to play was also suggested by Rantisi (2011) and enforced by Riegels Melchior (2011) to maximize the place-making ability of fashion designers. The second theme is how fashion design can contribute symbolically and economically to the development and international recognition of a place. All previous studies emphasized this contribution of fashion beyond the conventional approach of simply dressing the public. The third theme is the scale of place-making, which ranges from the scale of a neighborhood to that of a nation. Whilst earlier studies discussed the relationship between place and fashion at the level of city and nation (Rantisi 2011; Riegels Melchior 2011; Segre Reinach 2011; Skov 2011), McRobbie (2015) investigated it in a neighborhood in Berlin. 
Following these themes, for this study of Pre Helsinki, we conceptualize placemaking as the ability of fashion design that derives from collaborative efforts of diverse local actors in order to contribute to the development of local fashion scene with the purpose of creating a meaning for place to be recognized as a place of fashion on different scales from neighborhood to nation.

The contribution of this study is two-fold. First, it expands the academic discussion on place-making by emphasizing the role of fashion designers as catalyst of place-making and by distinguishing three themes in this concept that can be measured: collective efforts of local actors; their symbolic and economic contributions to the local fashion scene; and various scales of implementing place-making. More importantly, in the second place, this study applies the concept of place-making to the case of Pre Helsinki utilizing it as an explanatory case study. In the following section, we introduce the research methods, including approaches for data collection and interpretation. The three themes related to place-making will be further discussed in four aspects of the case, namely background and origin the platform as well as its main activities and actors. Then, external and internal challenges that the platform faces are discussed followed by the possibilities of future development. Lastly, this paper concludes with potential directions for studying fashion designers and place-making.

\section{Research Methods}

This investigation on the single-case of Pre Helsinki is illustrated in order to answer two questions: (1) what has influenced Pre Helsinki to emerge? And (2) how has the platform contributed to the development of local fashion scene with the purpose of increasing the international recognition of Finnish fashion? Altogether the results of this study will present the ways in which fashion designers contribute for Finland to joining the global dialogue on fashion. Adopting the basic principle of case study that suggests 
employing multiple sources of evidence (Yin 2013), for this inquiry, two qualitative research methods were employed, namely semi-structured interviews and ethnographic observation, in order to generate the main data set.

Throughout the purposive sampling approach (Flick 2009), the interviewees were selected by the criteria of their involvement in the platform and also suggestions from its co-founders. Total 12 interviews were conducted and the interviewees include co-founders, organizers currently working for the platform (creative director, branding director, $\mathrm{PR} /$ marketing director, among others), experts from both the local fashion school and industry (educators, consultants and prominent designer), fashion designers who have participated in Pre Helsinki programs as well as external partners (local collaborators including a ministry representative). In this research, we do not anonymize interviewees, who agreed to have their names identified (see Appendix 1). Furthermore, it is because of their specific roles played in the development and operation of Pre Helsinki.

The interviews were planned and prepared aiming at identifying key aspects for the case. In advance to each interview, secondary data sources, such as news media, website and social media, were viewed to understand background of the interviewee and to construct relevant questions. Additionally, several topics were discussed with every interviewee. These topics include personal opinions about the Finland and Helsinki fashion scene, his/her relationship with the platform and its future scenarios. Diverse angles of opinions based on individually different expertise and experience helped us have a holistic and objective view for the study.

In addition to the interviews, ethnographic observation were made during the Pre Helsinki program in 2016 from May 20th to 28th. The entire program was followed and documented through both field notes and photographs. The format of events in the 
program varied from exhibition, fashion show, showcase, pop-up store opening, workshop to party (see Appendix 2 for the observed program in 2016).

Furthermore, mediated data about the platform was collected throughout the program in 2016. This data was not produced for this particular study but published either digitally or in printed form to communicate the program to larger audiences. The spectrum of this data includes texts and visual materials from official communication channels of Pre Helsinki 2016, such as brochures, website ${ }^{\mathrm{v}}$ and social media ${ }^{\mathrm{vi}}$. Several news and fashion media articles as well as blog posts about the platform were also added. However, these materials were only used as supportive information for this study.

The recorded interviews were transcribed and combined with field notes from the observation as the main set of data. For the analytic process from the data set, theoretical thematic analysis (Braun and Clarke 2006) was employed to compare results between previous studies on the place-making ability of fashion design and the case of Pre Helsinki. This approach was useful as this study first identified main themes of place-making then further discovered key aspects of the case through the review of data set. Using the ATLAS software that helps digitize and organize the data, transcribed interviews and field notes were reviewed repeatedly to refine descriptions for the aspects. Throughout the triangulation of the investigators and evidence (Denzin 1978), the validity of the analysis was examined. After constructing the descriptions, the authors of this study organized a series of discussions to further identify the connection with the themes of place-making. In iteration, the descriptions of emerged aspects were revised to present the concise illustration of the case that demonstrates the complex nature of place-making via fashion design. 


\section{Findings: past and present of Pre Helsinki}

In order to empirically investigate why Pre Helsinki emerged and the ways in which the platform has influenced the development of local fashion scene, it is imperative to unpack key aspects of the case. Thus, this section will provide the following findings related to Pre Helsinki, namely, background, origin, activities of the platform, and main actors. The first research question, what has influenced Pre Helsinki to emerge?, is related to the background and origin while the second question, how has the platform contributed to the development of local fashion scene?, is linked to the sections on activities and main actors of the platform. This section begins with the recognition of two disconnections existed in Finnish fashion and present two solutions that the cofounders of Pre Helsinki utilized to overcome these disconnections. Additionally, two approaches implementing the solutions are presented. Lastly, three main groups of actors (organizers, designers and external partners) are introduced. Regarding the structure of each aspect, an articulated explanation based on the analysis of data is presented first then relevant themes of place-making are discussed. Altogether, the case of Pre Helsinki functions as a window to view the ways in which it has constructed the meaning of Helsinki and Finland as places for fashion internationally.

\section{Background: two disconnections in Finnish fashion}

As mentioned above, Finnish fashion has recently experienced success in certain areas, especially through international fashion design competitions, where the artistic side of Finnish fashion was remarked. However, until the 2010s, one of the major issues -the global recognition of Finnish fashion- was not fully resolved. In this paper, we argue that there were two disconnections that prevent this recognition: (1) domestic level disconnection between design and business sides of Finnish fashion as well as (2) 
international level disconnection between the Finnish fashion scene and the rest of the fashion world. These disconnections were the drivers behind the emergence of Pre Helsinki.

The first disconnection arose from the domestic level, especially the business side of Finnish fashion. Based on the data, several gaps that influenced this issue were observed from the education to the professional field. Regarding the educational side, university level courses on fashion marketing and branding are recent in Finland and it is still not easy for fashion design students to apply the abstract knowledge to the practice of everyday business. On the professional side, large numbers of fashion designers in Finland are self-employed (Lille 2010; Van Eynde and Wiinamäki 2012) and struggle for many reasons: lack of financial resources and skills to manage a business and, in general, difficulties to build a team and to delegate tasks. Additionally, from the interview with business expert and educator Pekka Mattila, he noted that Finnish fashion designers tend to retain full control over their companies instead of sharing it with business experts. However, according to the interview with prominent designer and fashion educator Tuomas Laitinen, very few business professionals in Finland understand the fashion industry while young fashion designers have expanded their success stories through global fashion competitions. In other words, while the importance of training fashion designers to have business minded is noted, a more significant issue was identified from the lack of fashion friendly business expertise that can maximize the potential of Finnish fashion designers.

Until recently, the disconnection between the Finnish fashion scene and the broader context was already observable, because domestic events, such as Gloria Fashion Show ${ }^{\mathrm{vii}}$ and Helsinki Design Week ${ }^{\mathrm{viii}}$, were organized aiming at promoting fashion collections of local designers. These events have been either channelled mostly 
toward the local press or have focused on the broader design sector instead of specialized in fashion. The small domestic market restricted Finnish fashion entrepreneurs to grow internationally due to the lack of support (Lille 2010; Van Eynde and Wiinamäki 2012). Moreover, from the interview, Laitinen also pointed out that the Finnish fashion scene lost touch with the mainstream fashion landscape during the 1990s and 2000s. This became problematic with the fact that Finland is relatively isolated from the global industry not just geographically but also in many levels, including business mindset and sensibility to market trends. These approaches restricted the possibilities of Finland being recognized better on the global fashion stage.

In relation to the progression of Finnish fashion, the influence of two relatively recent historic events was identified from the interview with Finnish design historian Pekka Korvenmaa. First, the development of new Finnish fashion accelerated after the collapse of the Soviet Union in 1991 (see also Van Eynde and Wiinamäki 2012). Despite being short, this history of new local fashion provided freedom to explore something innovative and unique. Before the collapse, Finland was an important supplier of various goods to the Soviet Union, especially textiles. After the collapse, the Finnish garment and textile producers lost their biggest and most stable client. Second, Finland's participation of the European Union in 1995 challenged the local industry. With the intensified competition from outside the country, Finnish business owners needed to revise their approach to face the drastic change.

Beside these two context specific events for Finland, the competition between developed and developing countries for producing garments in lower cost was an additional factor forcing Finnish fashion actors to rethink their future directions. As a result, the domestic production scale for garments was decreased significantly and small design-oriented firms with strength in craftsmanship began emerging in Finland around 
the 2000s (Korvenmaa 2010; Hohti 2011). During the interview, prominent Finnish designer Vuokko Nurmesniemi noted that having a strong tradition in artistic approach to design and material knowledge from workshop based practice, Finland possesses a firm foundation for building a new wave of fashion as a distinctive national product on the global fashion market. Despite of this promising potential, this stage of Finnish fashion only confirms an absent condition of relevant activities for place-making. These domestic and international level disconnections restricted the local fashion industry to grow whilst also providing a foothold for a new initiative to step into.

\section{Origin of Pre Helsinki: two solutions to reconnect}

As introduced in the previous section, the absence of diverse crucial factors in order to internationalize Finnish fashion was observed, including fashion-oriented business expertise in Finland, networking beyond local community, and fashion specific promotion effort for reaching broader markets. As an effort to overcome these disconnections from the Finnish fashion industry, Pre Helsinki was formed as a collaborative platform to address two particular issues: increasing the international visibility of Finnish fashion and developing the business side of local fashion to be more fashion-friendly.

Originally the idea of Pre Helsinki emerged as a start-up business by three master's level fashion design students from Aalto University ${ }^{\text {ix }}$ (Satu Maaranen, Sofia Järnefelt and Vilma Pellinen) who later became co-founders of the platform. In early 2012, they participated in the Fashion Business program organized by Aalto University Department of Design partnered with Aalto Center for Entrepreneurship. In the interview with Finnish fashion educator Pirjo Hirvonen who was involved in the program, she explained that the program was a special competition to spin out new fashion based start-ups that would provide more visibility for Finnish fashion business 
and entrepreneurship. During the program, the students received coaching sessions with influential experts ${ }^{\mathrm{x}}$ from the local industry and identified gaps and opportunities to be filled. That was the moment when the idea of Pre Helsinki originated. Based on the interview with Satu Maaranen, one of these three fashion students, apart from the fact that many fashion weeks are already established worldwide, they learned that Helsinki is too small to hold such an event. They also recognized that in conventional fashion weeks, participants and visitors are involved in a hectic schedule running between fashion shows and other events organized by different fashion houses. In contrast to this fast-paced schedule, the students wanted to offer a different experience: more personal and relaxed, in order to provide chances to visitors to better understand the quality of designers' work and the idea behind the design. They aimed at creating an engaging fashion event where the visitors are able to spend time to see the clothes carefully, meet and get to know the designers, and learn about history and background of Finnish design in Helsinki. In order to achieve this, they needed to collaborate with experts who understand the business of fashion.

While participating this program, the three students met two marketing experts (Miia Koski and Martta Louekari) who worked for the office of World Design Capital $(\text { WDC })^{\text {xi }}$. In fact, the year of 2012 was very important for many local stakeholders of design beyond fashion as the city of Helsinki was selected as the WDC. For this reason, the WDC Helsinki office organized a wide spectrum of events around design, some of which, focusing on fashion, aimed at introducing a fashionable side of the city to international visitors. These events included Aalto University fashion show of students and alumni as well as Marimekko ${ }^{x i i}$ public fashion show. From this experience in 2012, both the design and business sides recognized not just a strong need for collaboration 
but also an opportunity for developing an international platform that can promote Finnish fashion design globally.

As a result, in May 2013, three fashion designers who graduated from Aalto University and two marketing experts who worked for the WDC office joined forces to create something new for the city: the first Pre Helsinki program. From the interview with one of co-founders Koski, she explained the dual meaning of name. It evokes both the ambition of Helsinki becoming a fashion city and the timing of the event, which coincides with the pre-collection season in the fashion calendar. Throughout this new platform, both internationalization of Finnish fashion and establishment of local cooperation between fashion design and business were partially addressed. Accordingly, interviewed experts (e.g. Mattila and Lindberg-Repo) noted that, soon after the initiation, it was considered as the first internationally recognized fashion event from Finland as it offered an opportunity for Finnish fashion designers to network beyond local media and actors. This early stage of Pre Helsinki shows place-making in the domestic level as a preparation for reaching the global.

As earlier studies presented (Rantisi 2011; Segre Reinach 2011; Skov 2011; McRobbie 2015), the symbolic and economic contributions in the development of local fashion scene are key attributes in the place-making ability of fashion design. The story of how the platform originated presents its primary contribution in symbolic dimension through active promotion of Finnish fashion talents. Although the importance on the economic contribution was not initially emphasized, the cultivation of fashion specific local business expertise is a noticeable factor. The issue with the lack of commercial implication in this platform will be introduced further in following sections.

\section{Platform: how it works}

The two solutions for overcoming this challenge of connecting the local and the global 
was identified while viewing the ways in which Pre Helsinki has been operated. The main activities of the platform include a set of events, in which a number of Finnish fashion designers participate. The events differ in format. The platform organizes showcases of designers in Helsinki and abroad (e.g. Paris and Shanghai) as well as design workshops and pop-up store for general public. Thus, it serves as a platform that relies on the work of fashion designers and leverages resources from different sectors of Finland and develops a series of events to increase the visibility of the Finnish fashion talents domestically and, more importantly, globally.

Linking the scale of place-making to the platform, two approaches were observed. For the annual program that invites international guests to Helsinki, the city has been utilized to represent the Finnish fashion scene as most stakeholders and the fashion industry in Finland are centralized there. Thus, by organizing programs in the city, the platform has been able to increase visibility of Helsinki and of Finnish fashion to international visitors. Conversely, for the programs that bring designers to other fashion events outside the country (e.g. Paris and Shanghai), Pre Helsinki has acted as an active agent of promoting the city and the new identity of Finland as fashion nation. This latter approach also functions to attract international visitors, such as media and buyers, to Helsinki.

Since the first program in 2013, the promotion of young Finnish fashion designers has been the main goal of the organization, instead of direct sales of products from designers. Whilst this absence of sales has allowed a new initiative to emerge more recently, its focus on symbolic promotion of Finnish fashion through global media has helped the platform to partially achieve its goal. To differentiate Pre Helsinki from other fashion events in Finland and nearby countries, diverse events that can maximize the experiences of international fashion press have been organized (e.g. Rantisi 2004; 
Skov 2011). Interviewed co-founders (Maaranen and Koski) noted the importance of organizing events in Helsinki to increase visibility of local fashion. Additionally, during the interview, branding expert Kirsti Lindberg-Repo argued that experiencing Finnish fashion in the city can give a positive impact on overall experience of international guests. Pre Helsinki has changed its program annually but the central idea remained the same (see Appendix 2 to view the full list of activities in Pre Helsinki 2016). Since the beginning, the platform has created its own activities, such as presentation of designers and pop-up store. These activities have been designed by participating designers for the international guests; thus intending to demonstrate the unique work of Finnish fashion designers (see Figure 1). To be able to invite highly influential guests, such as fashion editors from international editions of Vogue and Elle, among others ("Pre Helsinki" 2016), the organizers have cooperated with the Ministry of Foreign Affairs. These visits of foreign journalists and their articles in renowned global media have been considered as the measure of success in achieving the goal of global recognition.

[Figure 1 near here]

Alongside this hosting program in Helsinki, Pre Helsinki has also offered their designers opportunities to reach out other markets. Bringing their designers abroad is another way to increase visibility of Finnish fashion. For instance, group presentations during Paris Fashion Week are organized annually since 2013 as well as outreach programs to Asian cities, such as Shanghai and Hong Kong. Paris Fashion Week is crucial for the platform as influential journalists and buyers of the global fashion scene attend the event. Meanwhile, the outreach program has offered 'matchmaking' services to individual designers of the platform. This program is usually conducted based on meetings with individual designers that aim at understanding their particular needs. From the period of the trip and meeting arrangements with local companies, the 
platform has provided individually catered services to increase the possibility of exporting Finnish fashion design.

In line with the studies of McRobbie (2015) and Skov (2011), this case shows a possibility to utilize the place-making ability of fashion design in multiple scales from city to nation. Pre Helsinki has contributed to the recognition of Finnish fashion at the local level by coordinating and developing various events aimed at attracting visitors under its roof. It has also contributed to the global recognition of Helsinki as a city for artistic fashion designers and Finland as a fashion nation through closely engaging with international visitors, such as fashion journalists, recruiters and buyers. This dual approach of Pre Helsinki, embracing the city and the nation as well as the local and the global contexts, introduces a strategy that different types of places can employ in order to maximize the opportunity that fashion design offers beyond dressing the public. By changing the scale depending on the context, Pre Helsinki has demonstrated an alternative yet carefully curated approach for reimagining places via fashion design.

\section{Main Actors: organizers, designers and external partners}

To achieve the goal of internationalizing Finnish fashion talents, Pre Helsinki has been built on complex relationships of three groups: organizers, designers and partners, each supporting different dimensions of Pre Helsinki. This section will further introduce the main actors involved in the platform as well as how they qualify to operate or support it. Lastly, the contribution of the platform will be reviewed in regards to its influence on local actors to the place-making of Helsinki/Finland and the involvement of local actors for both participating and supporting the platform.

Including both design and business sides of fashion has allowed the co-founders to construct Pre Helsinki with a holistic perspective. To develop and operate a series of programs, diverse tasks were required. Thus, it has been important to fully utilize 
expertise from different fields. Throughout interviews and the official website, the roles of the four organizers were identified, including creative director, treasurer, PR (public relations)/marketing director, and production/branding director. The creative director is responsible for the design side of the platform. Therefore, understanding the ways in which fashion designers and the fashion industry work is the key consideration for this job. The PR/marketing director works to communicate externally, especially with international visitors while the production/branding director is usually involved in coordinating partners for diverse programs of the platform. During the program in Helsinki, the production/branding director also takes responsibility to oversee activities that require constant coordination. Lastly, the treasurer manages the overall finances and administrative works for its activities. This internal organization of the platform shows the strong intention for supporting its designers, especially with the emphasized PR and marketing expertise. It also addressed the previously discussed issues of Finnish fashion, including the disconnection between design and business in the local as well as the disconnection between local and global fashion.

The second group of important actors in Pre Helsinki is the fashion designers. As it aims at internationalizing Finnish fashion talents, the ways in which the platform selects participating designers have been a crucial issue. It originated from the alumni fashion show of Aalto University in 2012 during the WDC. Naturally, in the earlier stage, the participating designers were mostly from Aalto University. The recent success at several international fashion competitions is also tied to this university. As the platform evolved towards supporting the overall Finnish fashion rather than a specific group of designers, the organizers developed a selection criteria for designers. The key rule is that a candidate has to have connection to Finland and some international visibility with relevant personal network to contribute to the platform. Throughout this 
selection, the platform both reinforces the reputation of Finnish fashion, which is often associated with artistic and textile driven works according to the interview with Koski, and introduces new breeds of designers continuously. On the one hand, selected designers present their works in multiple programs, such as Sasu Kauppi, ensæmble, Lepokorpi and Juslin Maunula (see Appendix 3). This helps both designers and organization to show the development of their work as well as continuity through consistency. On the other hand, partial changes on the list of participating designers help the platform to avoid stagnation.

External partners have also been a very important group of actors in supporting Pre Helsinki. Establishing the internal organization with both design and business sides of fashion provided a foothold for the platform but in order to develop this cooperation further, a larger scale external support was vital. For this study, partners from the latest program, held in May 2016, was investigated to exemplify the case. According to the interviews with three organizers of 2016 program and the official website, key partners were identified, including Aalto University, Marimekko, funding agencies in Finland as well as local companies. It was observed that each partner had different relationship with the platform.

Aalto University has been the most important partner for Pre Helsinki. Not only the idea of the platform started at the University, but also many participating designers graduated from it. Before the launch of Pre Helsinki, the student fashion show of Aalto University (Näytös in Finnish, see Figure 2) already attracted international guests due to both the recent success of Aalto University fashion students in winning international competitions and the strong network of Tuomas Laitinen. Since 2010, Laitinen has been at the university as a lecturer but his personal connections were built through previous experiences from his studies at Central Saint Martins in London and works as fashion 
designer in Paris. Besides his current role at the university, he has also worked as fashion editor at the SSAW magazine since its launch during WDC in 2012. For these reasons, it has been natural for the platform to include Aalto University fashion show as one of main activities in its program.

[Figure 2 near here]

Together with this educational root, Pre Helsinki has not forgotten its strong local heritage, which comes from Marimekko. The brand has been considered as the representation of Finnish fashion since its golden era in the 1950s and 1960s (Ainamo 1996). More recently, its annual public fashion show has become a festive tradition for Helsinki to celebrate the beginning of the summer season since its first introduction in 1992. Due to the importance of the label within the Finnish fashion scene, the platform has been also starting its program in Helsinki with this public fashion show of Marimekko. More than this symbolic importance of the brand, it has provided professional experiences to young local designers. Including several designers from the platform, many designers have entered the professional field through the brand. ${ }^{\text {xiii }}$ Other than these two symbolic partners of the platform, governmental and private funding agencies in Finland recently provided practical support. With the goal of internationalizing Finnish fashion talents, Pre Helsinki has successfully awarded grants from funding agencies, such as the Finnish Cultural Foundation since its launch and receiving support from governmental organizations, especially the Ministry of Foreign Affairs. This result signifies that these actors began recognizing the effort of Pre Helsinki and its potential as a vehicle for promoting the country and its culture. What is noticeable from this case is that the governmental support for the platform is only limited in comparison to other cases, such as Danish fashion where the government 
developed a clear supporting program for fashion (Riegels Melchior, Skov and Csaba 2011).

Additionally, in 2016, numerous local partners showed their supports during the program in Helsinki. For instance, Artek, a Finnish furniture manufacturer of iconic products, offered its flagship store in Helsinki as a pop-up store to showcase products of Pre Helsinki designers together with Artek items. The local branding agency Duotone was also involved in the 2016 program to produce high-quality multimedia footage, including video clips and photographs, to distribute to the international press.

These various supports demonstrated the impact of the platform in initiating dynamic interaction among different actors in the local scale in order for the regional actors to realize Helsinki and Finland as places for fashion and collaborate to join its vision (Rantisi 2011; Riegels Melchior, Skov and Csaba 2011). Following Figure 1 illustrates the dynamic relationship among the three main groups of actors. Through different types of arrows, it depicts how the intensity of the relationship differs among the groups.

[Figure 3 near here]

As depicted from the figure, we can argue that this development of the local fashion ecosystem has been a by-product of the platform. Previous studies on place-making emphasized the importance of cultivating active involvement of local actors (Rantisi 2011). It is clear that, from its launch to the current stage, Pre Helsinki has mobilized local actors in different fields, such as educational, governmental, cultural and corporate organizations. Throughout its programs in and outside Finland, it has bridged actors to strive for the goal of internationalizing Finnish fashion talents. Moreover, it has reconnected existing capabilities in Finland through its programs. By strengthening the relationship among the local actors, the platform also contributed to the local ecosystem 
to realize the potential of Finnish fashion beyond its design heritage.

\section{Discussions on Challenges: the business side of fashion}

This section is devoted to the problems and forthcomings faced by Pre Helsinki. As the platform has the status of not just a trailblazer but also a start-up, it is natural to encounter diverse challenges to overcome. One of its initial goals, to increase international visibility of Finnish fashion, has been addressed through a joint effort of local stakeholders, which can be observed from the growing coverage of Finnish fashion in international media. Recently, major fashion magazines, including Vogue Italia, W Magazine, i-D, Dazed and Women's Wear Daily, introduced young Finnish designers and Pre Helsinki (Bottenghy 2016; Gush 2016; Stansfield 2016; Voight 2016; Wynne 2016). However, the economic growth of Finnish fashion has been restricted due to its stagnated exports of fashion goods (Lille 2010; Van Eynde and Wiinamäki 2012). These two contributing dimensions, the symbolic through increased global recognition and the economic through increased sales and export, are equally relevant for the place-making of Helsinki/Finland as places of fashion. Accordingly, major tensions are perceived from the business side of the platform both internally and externally.

In regards to internal tension, the first issue has occurred from the difficulty of self-sustaining. As several experts noted, the lack of strong business implications is a threat to Pre Helsinki format. The absence of direct sales and strong reliance to external funding urges the organization to evolve. In consequence, the second issue stemmed from this call for change. From the 2015 program, the platform experienced organizational changes as two founding members with marketing, PR and communication background left their positions. With the newly recruited organizers, strategic developments are expected to be initiated in the following years. 
While experiencing this internal change, a strong competitor arose externally. Juni, a consulting company, was launched in 2015 to support the broader cultural industry, including fashion and design. The two members who left Pre Helsinki founded the company; thus similarities between the two organizations in certain level were observed, such as the format, activities and partners. However, it has a differing goal to provide financial success for Finnish fashion and design companies. In order to achieve this goal, Juni launched Helsinki New, a showcase of local fashion companies. It includes a broad range of companies apart from a group of selective designers/brands. While coordinating diverse events independently organized by participants, the Helsinki New showcase brought a larger number of international guests, especially from the Asian market. ${ }^{\text {xiv }}$ The showcase also organizes a series of events outside Finland for Finnish designers and brands to export their products in emerging markets, especially East Asia. With this competitor, the approaches developed by Pre Helsinki have faced challenges.

These internal and external changes will surely influence programs of Pre Helsinki to develop and improve its business agenda in the future. Based on Falay et al. (2007) who studied multiple cases of Finnish design-intensive firms, the partnership between design and business experts is crucial for them to sustain competitiveness while growing internationally. Moreover, such partnerships are especially important once the initial stage of establishment is achieved and the second stage of growth is required. Similarly, the changes from the initial stage of Pre Helsinki were a sign to prepare for the next stage not just to sustain its current achievement but also to develop further. The reconstruction of the internal organization will initiate a new phase of the platform with stronger business implications at the same time as its foundational value, to support the Finnish fashion talents, stays the same. The competition with Juni will 
encourage the organization to identify new strategies while differentiating from the Helsinki New showcase or, instead, consolidating the efforts of the two platforms. Altogether these changes will cultivate a healthier fashion ecosystem in Finland.

\section{Conclusion}

The objective of this paper was to view how the concept of place-making works in the case of the platform Pre Helsinki in Finland. Three themes for the concept were identified. Accordingly, we considered place-making as an ability of fashion that derives from collaborative efforts of diverse actors aimed at pushing fashion industry forward. In the case of Pre Helsinki, such actors, including fashion designers, state officials, educators, and other professionals, were mobilized by the platform. This case was investigated in details with particular attention to its background, origin, how the platform works and its main actors. It was argued and shown that the emergence of the platform was a response to two disconnections that are peculiar to the Finnish fashion context: the disconnection between fashion design and business and the disconnection between local and global fashion scenes. Pre Helsinki addressed these tensions offering a set of activities aimed at promoting Finnish fashion internationally. It was demonstrated that the disconnection between fashion design and business was addressed only to a limited extent, which allowed a new, competing platform, Helsinki New, to appear.

Alongside the organic development of Pre Helsinki, the gradual internationalization of Finnish fashion has occurred. In 2016, Finnish fashion designers succeeded again in global competitions and some expansion of several Finnish fashion brands, such as Samuji, R/H, Minna Parikka and ONAR Studios, towards the international market has been observed. Furthermore, from the education side, Aalto University was ranked highly on the global fashion school ranking of the Business of 
Fashion in 2016 and 2017. Altogether, these achievements have influenced governmental funding agencies, such as TEKES (Finnish Funding Agency for Innovation), to support local fashion firms. Accordingly, this case study exemplifies that Pre Helsinki has played a significant role as a grass-root initiative to contribute to both mobilizing local actors and building a meaning for Helsinki and Finland as places of fashion. Then, what path shall this platform follow?

According to the study of Riegels Melchior, Skov and Csaba (2011) on the development of Danish fashion, four stages are identifiable. These stages include (1) problematization (adjustment to deindustrialization and the emergence of a designer fashion sector); (2) interessement (government's gradual reinterpretation of the cultural sector, especially fashion as an innovative industry worth of support); (3) enrolment (stabilization of networks and establishment of a leading institute) and; (4) mobilization of allies (leading politicians' promotion of local fashion). Reflecting on these stages, the current transitional stage of Finnish fashion is in between the second and the third stage since the government has started recognizing the value of Finnish fashion industry while local actors managed to mobilize and organize Pre Helsinki. Comparing to Denmark, Finland still lacks a leading institute that can unify all local actors in order to further promote the Finnish fashion scene. However, Finnish fashion does not necessarily follow the same development trajectory as Denmark because the Finnish local ecology, such as production facilities, the size of domestic market and educational emphasis, is very distanced from the Danish context. Pre Helsinki and its activities have already represented the unique path that Finland has constructed and recognize pluralistic scenarios for increasing the international recognition. Although the platform has faced challenges due to internal and external changes, it can be argued that this unsettled and evolving status of the platform resembles the nature of fashion. Surfing on 
this ephemeral of fashion (Lipovetsky 1994), its process of making a place is still in progress. Whether Finnish fashion becomes the next fashion nation or not, the case of

Pre Helsinki has already contributed to global fashion by demonstrating an alternative possibility with its distinctive designers-first approach.

\section{References}

Ainamo, Antti. 1996. Industrial Design and Business Performance. Doctoral Dissertation. Helsinki: Helsinki School of Economics and Business Administration.

Bottenghi, Francesca. 2016. "A Special Diary from Helsinki". Vogue Italia. http://www.vogue.it/vogue-talents/news/2016/06/01/a-special-diary-fromhelsinki/.

Braun, Virginia and Victoria Clarke. 2006. "Using Thematic Analysis in Psychology". Qualitative Research in Psychology 3 (2): 77-101.

Chun, Namkyu, Olga Gurova, and Kirsi Niinimäki. 2017. "Rethinking the Roles of Fashion Designers: The Case of Pre Helsinki". The Design Journal 20 (sup1): S4477-S4486.

Colliander, Oona. 2015. The Finnish Fashion Entrepreneurship Ecosystem. Master's Thesis. Helsinki: Aalto University School of Arts, Design and Architecture. Crewe, Louise. 2017. The Geographies of Fashion: Consumption, Space, and Value. London: Bloomsbury Academic.

Davies, Kevin. 2002. "'A Geographical Notion Turned into an Artistic Reality': Promoting Finland and Selling Finnish Design in Post-War Britain C.1953 1965". Journal of Design History 15 (2): 101-116.

Denzin, Norman K. 1978. The Research Act: A Theoretical Introduction to Sociological Methods. New York: McGraw-Hill.

Falay, Zeynep, Markku Salimäki, Antti Ainamo, and Mika Gabrielsson. 2007. "DesignIntensive Born Globals: A Multiple Case Study of Marketing Management". Journal of Marketing Management 23 (9-10): 877-899.

Flick, Uwe. 1998. An Introduction to Qualitative Research. London: Sage. Gimeno-Martínez, Javier. 2007. "Selling Avant-Garde: How Antwerp Became a Fashion Capital (1990-2002)". Urban Studies 44 (12): 2449-2464. 
Gimeno-Martínez, Javier. 2011. "Restructuring Plans for the Textile and Clothing Sector in Post-Industrial Belgium And Spain". Fashion Practice 3 (2): 197-224.

"Global Fashion School Rankings 2016". 2016. The Business of Fashion.

https://www.businessoffashion.com/education/rankings/2016.

"Global Fashion School Rankings 2017". 2017. The Business of Fashion.

https://www.businessoffashion.com/education/rankings/2017.

Grayson, Denise. 2013. "Helsinki's Aalto University to Give Creative Currency Fashion Seminar \& Show". The Swelle Life.

http://www.theswellelife.com/swelle_life/2013/05/helsinkis-aalto-university-togive-creative-currency-fashion-seminar-show.html.

Gurova, Olga and Daria Morozova. 2016. "A Critical Approach to Sustainable Fashion:

Practices of Clothing Designers in the Kallio Neighborhood of Helsinki".

Journal of Consumer Culture, 146954051666822.

Gush, Charlotte. 2016. "Näytös 16: Helsinki’s Freshest Fashion Talent Hit the

Runway". $i$-D. https://i-d.vice.com/en_gb/article/nyts-16-helsinkis-freshest-

fashion-talent-hit-the-runway?utm_source=idfbuk\&utm_campaign=global.

Hauge, Atle, Anders Malmberg, and Dominic Power. 2009. "The Spaces and Places of

Swedish Fashion". European Planning Studies 17 (4): 529-547.

Hauge, Atle. 2012. "Creative Industry: Lacklustre Business - Swedish Fashion Firms'

Combination of Business and Aesthetics as a Competitive Strategy". Creative

Industries Journal 5 (1): 105-118.

Hohti, Paula. 2011. Boundless Design: Perspectives of Finnish Applied Arts. Helsinki:

Avain / Ornamo.

Korvenmaa, Pekka. 2010. Finnish Design: A Concise Story. Helsinki: University of Art and Design.

Lille, Kirsi. 2010. Tevallako Tulevaisuuteen. Helsinki: Diges Ry.

Lipovetsky, Gilles. 1994. The Empire of Fashion: Dressing Modern Democracy.

Princeton, NJ: Princeton University Press.

Löfgren, Orvar and Robert Willim. 2005. Magic, Culture, and the New Economy. Oxford: Berg.

McNeil, Peter. 2017. "Report from Finland: Luxury and Museum Exhibitions in the Year "100 Years of Finland," with a Focus on "Pitsi on Pop/Lace and Luxury": Curators Marjatta Hietaniemi and Anne-Maj Salin (Salo Art Museum/Salon Taidemuseo, West Finland)". Luxury 4 (2-3): 313-323. 
McRobbie, Angela. 1998. British Fashion Design: Rag Trade or Image Industry?. London: Routledge.

McRobbie, Angela. 2015. Be Creative: Making a Living in the New Culture Industries. Cambridge: Polity.

Moreno, Victor. 2015. "Helsinki, Fashion's Healthy Wealthy Bubble". Metal Magazine. http://metalmagazine.eu/en/post/interview/tuomas-laitinen-helsinki-fashionshealthy-wealthy-bubble.

Niessen, Sandra, Ann Marie Leshkowich, and Carla Jones. 2003. Re-Orienting Fashion: The Globalization of Asian Dress. Oxford: Berg.

Pechman, Alexandra. 2016. "Tuomas Laitinen's Finland". Visionaire Blog. https://www.visionaireworld.com/blog/tuomas-laitinens-finland/.

Petersen, Lars. 2015. "Meet Finland's Rising Fashion Stars". W Magazine. http://www.wmagazine.com/gallery/new-finnish-fashion-designers/all.

Pöppönen, Hannu. 2016. "It's Time for Finnish Fashion to Take the Big Leap". Helsinki Design Week. http://www.helsinkidesignweek.com/weekly/its-time-for-finnishfashion-to-take-the-big-leap/?lang=en.

"Pre Helsinki". 2017. Pre Helsinki. http://www.prehelsinki.fi.

Rantisi, Norma M. 2010. "The Geography of Producing and Marketing Design for Montreal Fashion: Exploring the Role of Cultural Intermediaries". In Industrial Design, Competition and Globalization, 93-116. Palgrave Macmillan.

Rantisi, Norma M. 2011. "The Prospects and Perils of Creating a Viable Fashion Identity". Fashion Theory 15 (2): 259-266.

Riegels Melchior, Marie. 2010. "'Doing” Danish Fashion: On National Identity and Design Practices of a Small Danish Fashion Company". Fashion Practice 2 (1): $13-40$.

Riegels Melchior, Marie. 2011. "From Design Nations to Fashion Nations? Unpacking Contemporary Scandinavian Fashion Dreams". Fashion Theory 15 (2): 177-200.

Riegels Melchior, Marie, Lise Skov, and Fabian Faurholt Csaba. 2011. "Translating Fashion into Danish". Culture Unbound 3 (2): 209-228.

Salonoja, Noora. 2013. Bridging the Equity and Entrepreneurial Gaps in the Finnish Fashion Industry: A Comparative Case Study of the Swedish, Danish and Finnish Fashion Ecosystems. Master's Thesis. Helsinki: Aalto University School of Business. 
Segre Reinach, Simona. 2011. "National Identities and International Recognition." Fashion Theory 15 (2): 267-272.

Sjöroos, Mirva. 2016. "Finnish Fashion Embodies Playful Minimalism". Helsinki Design Week. http://www.helsinkidesignweek.com/weekly/finnish-fashionembodies-playful-minimalism/?lang=en.

Skov, Lise. 2001. Stories of World Fashion and the Hong Kong Fashion World. Doctoral Dissertation. University of Hong Kong (Pokfulam Road, Hong Kong). Skov, Lise. 2003. "Fashion-Nation: A Japanese Globalization Experience and a Hong Kong Dilemma". In Re-Orienting Fashion: The Globalization of Asian Dress, 215-242. Oxford: Berg.

Skov, Lise. 2011. "Dreams of Small Nations in a Polycentric Fashion World." Fashion Theory 15 (2): 137-156.

Stansfield, Ted. 2016. "Finland's Fashion Talents of Tomorrow Stage Show in Helsinki". Dazed. http://www.dazeddigital.com/fashion/article/31458/1/finlands-fashion-talents-of-tomorrow-stage-show-in-helsinki.

Szmydke, Paulina and Laurent Folcher. 2013. "Finnish Up: Finland's Fashion Moment". Women's Wear Daily. http://wwd.com/fashion-news/designerluxury/finnish-up-7283485/.

Takkinen, Tua. 2015. Profiting from Innovation in International Markets: Case of Finnish Fashion Industry. Master's Thesis. Oulu: University of Oulu.

Teunissen, José. 2011. "Deconstructing Belgian and Dutch Fashion Dreams: From Global Trends to Local Crafts". Fashion Theory 15 (2): 157-176.

Van Eynde, Frank, and Wilma Wiinamäki. 2012. Clothing and Textile Sector in Finland. Helsinki: Flanders Investment \& Trade.

Voight, Rebecca. 2016. "Helsinki's Finest: Meet the Designers to Watch from Finland". W Magazine. http://www.wmagazine.com/gallery/helsinki-finland-finnishfashion-designers.

Wynne, Alex. 2016. "Pre Helsinki Highlights Finnish Design Talent in Paris". Women's Wear Daily. http://wwd.com/fashio n-news/fashion-scoops/pre-helsinkihighlights-finnish-design-talent-in-paris-10608387/.

Yin, Robert K. 2013. Case Study Research: Design and Methods (Applied Social Research Methods). 5th ed. Thousand Oaks: SAGE Publications. 


\section{Appendices}

\section{Interview Participants}

\begin{tabular}{|c|c|c|c|}
\hline Name & Role at Pre Helsinki & Job & Note \\
\hline Satu Maaranen & $\begin{array}{l}\text { Creative Director, Co- } \\
\text { Founder }\end{array}$ & $\begin{array}{l}\text { Fashion designer at } \\
\text { Marimekko }\end{array}$ & $\begin{array}{l}\text { Head designer of ready-to-wear at } \\
\text { Marimekko }\end{array}$ \\
\hline Miia Koski & $\begin{array}{l}\text { Project Manager and } \\
\text { Producer, Co-Founder }\end{array}$ & Consultant at Juni & Co-Founder of Juni, a consulting firm \\
\hline Martta Louekari & $\begin{array}{l}\text { PR Director, Co- } \\
\text { Founder }\end{array}$ & Consultant at Juni & Co-Founder of Juni, a consulting firm \\
\hline Kirsti Lindberg-Repo & Expert & $\begin{array}{l}\text { Professor at Aalto } \\
\text { University in Branding }\end{array}$ & Teaching and consulting \\
\hline Pekka Mattila & Expert & $\begin{array}{l}\text { Professor at Aalto } \\
\text { University in Business }\end{array}$ & Teaching and consulting \\
\hline Tuomas Laitinen & Expert & $\begin{array}{l}\text { Senior Lecturer at Aalto } \\
\text { University, Fashion Editor } \\
\text { of SSAW magazine }\end{array}$ & Teaching and consulting \\
\hline Vuokko Nurmesniemi & Expert & Designer / owner at Vuokko & Former designer at Marimekko \\
\hline Laura Väinölä & $\begin{array}{l}\text { Brand Director, Event } \\
\text { Manager }\end{array}$ & $\begin{array}{l}\text { Creative Director at } \\
\text { Duotone }\end{array}$ & Newly joined for Pre Helsinki 2016 \\
\hline Maija Juutilainen & $\begin{array}{l}\text { PR and Marketing } \\
\text { Director }\end{array}$ & PR Manager at Zalando & Newly joined for Pre Helsinki 2016 \\
\hline Johanna Kotkajärvi & External Partner & $\begin{array}{l}\text { Staff at the Finnish Ministry } \\
\text { of Foreign Affairs }\end{array}$ & $\begin{array}{l}\text { Director at the Department for } \\
\text { Communications (Asia, Africa and the } \\
\text { Americas) }\end{array}$ \\
\hline Pirjo Hirvonen & Expert & $\begin{array}{l}\text { Professor at Aalto } \\
\text { University in Fashion } \\
\text { Design }\end{array}$ & \\
\hline Pekka Korvenmaa & Expert & $\begin{array}{l}\text { Professor at Aalto } \\
\text { University in Design and } \\
\text { Culture }\end{array}$ & Finnish design historian \\
\hline
\end{tabular}

\section{Observed Activities of the Pre Helsinki Program in 2016}

\begin{tabular}{|r|l|l|l|}
\hline No & \multicolumn{1}{|c|}{ Activity } & \multicolumn{1}{c|}{ Date } & \multicolumn{1}{c|}{ Organizer } \\
\hline 1 & Daniel Palillo "Mainly Portraits" Exhibition & May 20 & Designmuseo (Design Museum) \\
\hline 2 & Marimekko Public Fashion Show & May 20 & Marimekko \\
\hline 3 & Pre Helsinki Pop-Up Store Opening Breakfast & May 23 & Pre Helsinki and Artek \\
\hline 4 & Ville Varumo Exhibition "Playground" Open House & May 23 & Ville Varumo (photographer) \\
\hline 5 & Aalto ARTS Fashion Seminar & May 25 & Aalto University \\
\hline 6 & Tekstilli (Textile) 16 Exhibition Opening & May 25 & Aalto University \\
\hline
\end{tabular}




\begin{tabular}{|r|l|l|l|}
\hline 7 & Näytös 16 (Aalto University Fashion Show) & May 25 & Aalto University \\
\hline 8 & Pre Helsinki House Presentation & May 26 & Pre Helsinki \\
\hline 9 & Tekstilli 16 Exhibition Party & May 27 & Aalto University \\
\hline 10 & Pre Helsinki "Working Shop" & May 28 & Pre Helsinki and Artek \\
\hline
\end{tabular}

\section{Participated Designers and Labels for Pre Helsinki Programs}

\begin{tabular}{|c|c|c|c|}
\hline Type & Period & Location & Designers / Labels (Total Number) \\
\hline Hosting & May 2013 & Helsinki, Finland & $\begin{array}{l}\text { ensæmble, Heikki Salonen, Laitinen, Marimekko, R/H, Lepokorpi, Sasu } \\
\text { Kauppi and Siloa \& Mook (8) }\end{array}$ \\
\hline Outreach & $\begin{array}{l}\text { September } \\
2013\end{array}$ & Paris, France & Sasu Kauppi, ensæmble, Siloa \& Mook, Lepokorpi and Satu Maaranen (5) \\
\hline Outreach & February 2014 & Paris, France & Osma Harvilahti, Sasu Kauppi, ensæmble, Siloa \& Mook and Lepokorpi (5) \\
\hline Hosting & May 2014 & Helsinki, Finland & $\begin{array}{l}\text { ensæmble, Lepokorpi, Samuji, Satu Maaranen, Sasu Kauppi, Siloa \& Mook, } \\
\text { R/H and Marimekko (8) }\end{array}$ \\
\hline Outreach & $\begin{array}{l}\text { November } \\
2014\end{array}$ & Shanghai, China & ensæmble, Satu Maaranen and Siloa \& Mook (3) \\
\hline Hosting & May 2015 & Helsinki, Finland & $\begin{array}{l}\text { Lepokorpi, Sasu Kauppi, R/H, Samuji, ensæmble, Juslin Maunula, Satu } \\
\text { Maaranen and Elina Määttänen ( } 8 \text { ) }\end{array}$ \\
\hline Outreach & August 2015 & Paris, France & Satu Maaranen, Juslin Maunula and Lepokorpi (3) \\
\hline Outreach & $\begin{array}{l}\text { November } \\
2015\end{array}$ & $\begin{array}{l}\text { Shanghai and } \\
\text { Hong Kong, } \\
\text { China }\end{array}$ & ensæmble, Satu Maaranen, Juslin Maunula and R/H (4) \\
\hline Hosting & May 2016 & Helsinki, Finland & $\begin{array}{l}\text { Hanne Jurmu \& Anton Vartiainen, Satu Maaranen, Sophie Sälekari, } \\
\text { Mannisto.co, Sofia Järnefelt, ensæmble, Lepokorpi, Sasu Kauppi, Siiri } \\
\text { Raasakka, Achilles Ion Gabriel, Juslin Maunula and Tiia Sirén (12) }\end{array}$ \\
\hline Outreach & $\begin{array}{l}\text { September } \\
2016\end{array}$ & Paris, France & Aamu Salo, Hanne Jurmu, Juslin Maunula, Lepokorpi (4) \\
\hline Hosting & $\begin{array}{l}\text { May } \\
2017\end{array}$ & Helsinki, Finland & $\begin{array}{l}\text { Aalto International, SSSU by Sasu Kauppi, Hanne Jurmu, Satu Maaranen, } \\
\text { Aamu Salo, Ella Boucht, Lepokorpi, Achilles Ion Gabriel, Sophie Sälekari, } \\
\text { Sofia Järnefelt, Siiri Raasakka, Self-Assembly, Juslin Maunula and Tiia Sirén } \\
\text { (14) }\end{array}$ \\
\hline
\end{tabular}


Figure 1. Guests outside the presentation location of fashion designers during the Pre Helsinki 2016 program. Copyright: Author.

Figure 2. The Aalto University student fashion show in 2016, which has been grown its scale annually since its first presentation to international guests in 2012. Copyright: Author.

Figure 3. A visualization for main actors of Pre Helsinki and their relationship. Copyright: Author.

\footnotetext{
${ }^{\mathrm{i}}$ See the official website of the Hyères Festival: http://www.villanoailles-hyeres.com.

${ }^{\text {ii }}$ See the official website of the LVMH Prize: http://www.lvmhprize.com.

iii The Antwerp Six refers to six Belgian designers, including Walter Van Beirendonck, Ann
} Demeulemeester, Dries Van Noten, Dirk Van Saene, Dirk Bikkembergs, and Marina Yee. They graduated from the Royal Academy of Fine Arts from Antwerp between 1980 and 1981.

${ }^{\text {iv }}$ See master's theses on the Finnish fashion industry (Salonoja 2013; Colliander 2015;

Takkinen 2015) and a doctoral dissertation on Finnish fashion firm Marimekko (Ainamo 1996).

v The official website of Pre Helsinki: http://www.prehelsinki.fi.

${ }^{\text {vi }}$ The official social media channels of Pre Helsinki: https://www.facebook.com/PreHelsinki and http://instagram.com/prehelsinki.

${ }^{\text {vii }}$ Gloria is the leading local fashion magazine in Finland. Official website: http://www.gloria.fi.

${ }^{\text {viii }}$ See the official website of Helsinki Design Week: http://www.helsinkidesignweek.com.

${ }^{\text {ix }}$ Aalto University was launched in 2010 through a merge of three independent universities in Helsinki metropolitan area, such as Helsinki University of Technology, Helsinki School of Economics and University of Art and Design Helsinki, with a strong emphasis on multidisciplinary education.

${ }^{x}$ Many participants of this research were actually involved during this time of forming Pre Helsinki as industry experts, including Pekka Mattila, Kirsti Lindberg-Repo and Vuokko Nurmesniemi.

${ }^{x i}$ World Design Capital is a biennial city-scale event organized by International Council of Societies of Industrial Design to celebrate successful implementations of design in the city. See the official website http://wdo.org.

xii Marimekko is a Finnish fashion and textile company, which was launched in 1951. 
xiii In December 2017, Satu Maraanen was appointed by Marimekko as Head Designer of readyto-wear, bags and accessories. Thus, the stronger relationship between Pre Helsinki and the brand is expected. Previously, she had worked for the brand as a freelance designer over five years.

${ }^{\text {xiv }}$ Martta Louekari, one of co-founders of Juni, has a personal network in East Asia from her previous work experiences. 